\title{
The Features of Outpatient Schizophrenia Treatment in Lithuania
}

\author{
Simona Grigaraite ${ }^{1}$ Aistè Leleikiené ${ }^{2}$ \\ 1-Psychiatry Residency Programme, Vilnius University, Lithuania \\ 2- Kèdainiai Primary Mental Health Center, Lithuanian Sports University, Lithuania
}

\section{Introduction}

The fast development of antipsychotics leads to various treatment choices for patients with schizophrenia. Widespread use of high doses antipsychotics is often replaced by prescribing more than one antispychotic at the same time, as well as their combination with other types of psychotropic drugs $[1,2]$.

\section{Methods}

One-year data of 172 schizophrenia patients' medical records of visits to the primary mental health center were collected.

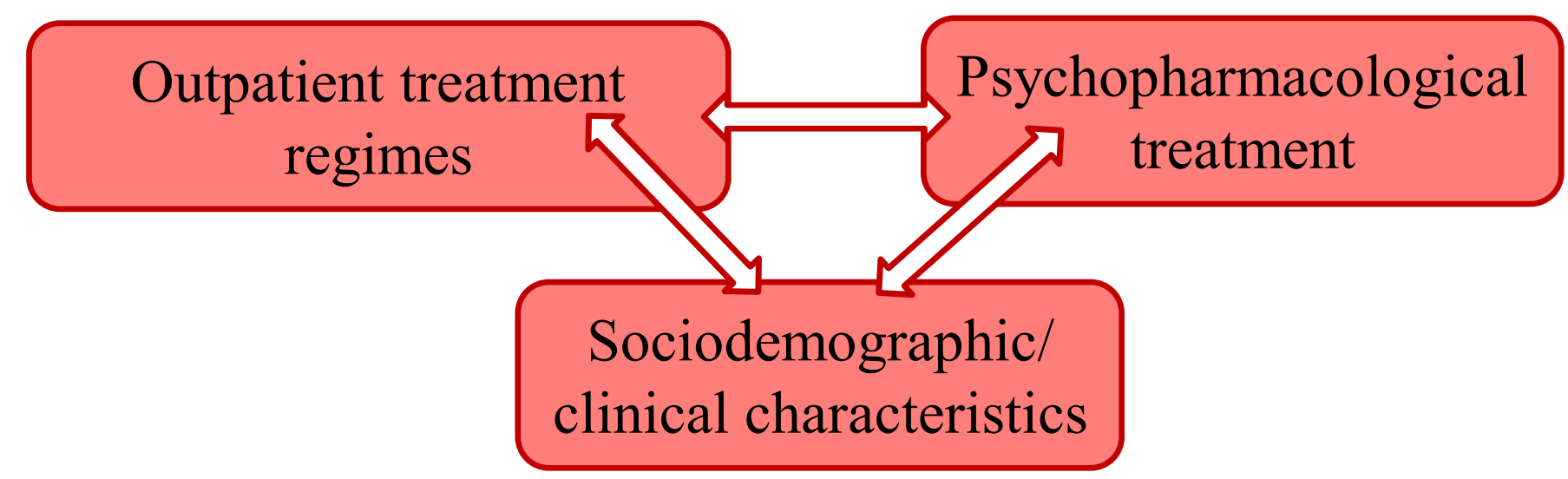

\section{Results}

- More than 40 different options for antipsychotic treatment were observed (Table 1)

- $58.1 \%$ of cases included polytherapy

- Longer illness duration led to a higher number of antipsychotic medications $(\mathrm{r}=0.188(\mathrm{p}<0.05)$

- The number of psychotropic medications got higher with higher number of visits to the primary mental health center $(r=0.195(\mathrm{p}<0.05)$

- Treatment corrections were more common with a lower number of hospitalizations $(\mathrm{p}<0.001)$

- Long-acting injectable antipsychotics were chosen in $22.2 \%$ of the cases

- $67.6 \%$ of corrected treatment cases included concomitant psychotropic medications

\section{Conclusion}

1. In more than half of schizophrenia cases outpatient treatment included polytherapy

2. The number of antipsychotic medications got higher with longer duration of mental illness

3. The number of psychotropic medications got higher with more frequent visits to the primary mental health center
Table 1. The most frequent outpatient antipsychotic treatment among study participants

\begin{tabular}{|c|c|}
\hline Antipsychotic medications & Frequency, \% \\
\hline Olanzapine & 14.5 \\
\hline Quetiapine & 14.0 \\
\hline Quetiapine and Risperidone & 9.9 \\
\hline Olanzapine and Risperidone & 8.7 \\
\hline Risperidone & 5.2 \\
\hline Haloperidol Decanoate and Olanzapine & 4.7 \\
\hline Olanzapine and Aripiprazole & 4.7 \\
\hline Quetiapine and Aripiprazole & 4.7 \\
\hline Paliperidone palmitate & 3.5 \\
\hline Haloperidol and Olanzapine & 2.3 \\
\hline Quetiapine and Ziprazidone & 1.7 \\
\hline Quetiapine and Amisulpiride & 1.2 \\
\hline Amisulpiride & 1,2 \\
\hline Haloperidol Decanoate and Risperidone & 1,2 \\
\hline Risperidone and Levomepromazine & 1,2 \\
\hline
\end{tabular}

1. Centorrino F, Eakin M, Bahk W-M et al. Inpatient antipsychotic drug use in 1998: comparisons to 1993 and 1989. Am. J. Psychiatr. 2002; Nov;159 (11):1932-35. 2. Keks NA, Altson K, Hope J et al. Use of antipsychosis and adjunctive medications by an inner urban community psychiatric service. Aust. N.Z. J. Psychiatry. 1999; Dec 1;33:896-01. doi. org/10.1046/j.1440-1614.1999.00639.x 